\title{
PRIMJENA UNUTARNJE TVORNIČKE KONTROLE KVALITETE ČELIČNIH PROIZVODA U SKLADU SA NORMOM HRN EN 1090
}

\author{
APPLICATION OF INTERNAL FACTORY PRODUCTION \\ QUALITY CONTROL OF STEEL PRODUCTS \\ ACCORDING TO HRN EN 1090 STANDARD
}

Rosanda Ivetić Salopek*, Ivan Marovićc* , Diana Car-Pušić ${ }^{* *}$

\begin{abstract}
Sažetak
Kvaliteta čeličnih proizvoda i postupci dokazivanja kvalitete u Republici Hrvatskoj zakonski su regulirani i određeni normom. S obzirom da je Hrvatska punopravna članica Europske unije, u obvezi je primjena Uredbe EU br. 305/2011 Europskog parlamenta i Vijeća te primjena grupe normi HRN EN 1090. Opsežnost postupka tvorničke kontrole kvalitete proizvodnje čeličnih elemenata zahtijeva odgovarajuće kvalificirano osoblje koje će kvalitetno provoditi sustav tvorničke kontrole kvalitete. U radu je prikazan kratak pregled grupe normi HRN EN 1090, njihova podjela te primjena u jednom tehnološkom procesu. Kroz primjer proizvodnje čelične konstrukcije budućeg trgovačkog objekta prikazan je postupak provođenja kontrole kvalitete prema normi HRN EN 1090-2 za klasu izvođenja EXC2. Sam postupak tvorničke kontrole proizvodnje čelične konstrukcije podijeljen je i analiziran u nekoliko ključnih faza: kontrola osnovnog materijala, pregled zavarivačke dokumentacije, pregled dimenzija, vizualni pregled, antikorozivna zaštita te izdavanje CE oznake ili Izjave o svojstvima. Svi procesi i postupci koji se odvijaju unutar tvornice su jednako važni kako bi se postigao konačni cilj, a to je kvalitetan čelični element sukladno normi HRN EN 1090 za buduću izgradnju građevina. Cilj ovog rada je ukazati na važnost provođenja tvorničke kontrole kvalitete, čime se bitno smanjuje mogućnost pograšaka, kako tijekom proizvodnje čeličnih elemenata, tako i u slučaju otkazivanja konstrukcije tijekom njenog korištenja.
\end{abstract}

\footnotetext{
*AR-METAL d.o.o. Žegoti 6, 51215 Kastav

E-mail: rosanda.ivetic@ar-metal.hr

${ }^{* *}$ Sveučilite u Rijeci, Građevinski fakultet, Radmile Matejčić 3, 51000 Rijeka

E-mail: \{ivan.marovic,diana.car.pusic\}@gradri.uniri.hr
} 
Ključne riječi: kontrola kvalitete, proizvodni procesi, HRN EN 1090, proizvodnja čeličnih elemenata

\begin{abstract}
The quality of steel products and quality assurance procedures in the Republic of Croatia are legally regulated and standardized. Since Croatia is a full member of the European Union, it is obligatory to apply the EU Regulation no. 305/2011 of the European Parliament and of the Council and the application of the standards group HRN EN 1090. The scope of the factory production control process of producing steel elements requires the appropriate qualified personnel in order to implement the factory quality control system. The paper presents a brief overview of the HRN EN 1090 standards group, their classification and application in a single technological process. Through the example of the steel construction of the future commercial building, the procedure of performing quality control according to HRN EN 1090-2 for the EXC2 performance class is shown. The manufacturing process of the steel structure during factory production control is divided and analyzed in several key phases: basic material control, welding documentation overview, dimension inspection, visual inspection, anti-corrosion protection and CE marking or declaration of properties. All the processes and procedures that take place within the factory are equally important to achieve the final goal, that is, a quality steel element according to standard HRN EN 1090 for the future building construction. The aim of this paper is to point out the importance of carrying out the factory quality control, which significantly reduces the possibility of failures, both during the production of steel elements as well as during its use in the case of the construction breakdown.
\end{abstract}

Key words: quality control, production processes, HRN EN 1090, production of steel elements

\title{
1. Uvod
}

Tvornička kontrola kvalitete čeličnih proizvoda važan je čimbenik za postizanje kvalitete u proizvodnji kako bi se dobio proizvod koji je siguran i ispravan za korištenje. Kvaliteta čeličnih proizvoda i postupci dokazivanja kontrole kvalitete bitno ovise o tome na koji način će se ona provoditi te koliko je osoblje koje ga provodi kvalificirano. Svaki čelični proizvod prije ugradnje i korištenja prolazi niz kontrola kojima se dokazuje njegova sigurnost i kvaliteta. Pritom je vrlo bitno bilježiti svaki postupak koji se provodi u vidu smanjenja troškova u proizvodnji te uklanjanja nedostataka u ranim fazama proizvodnje prije nego što proizvod izađe iz tvorničkog pogona.

Najveća važnost kod tvorničke proizvodnje čeličnih proizvoda pridaje se spojevima prvenstveno iz konstruktivnih razloga. Navedeni dio kontrole spojeva je vrlo zahtjevan zbog različitih metoda ispitivanja materijala i opreme koja pritom koristi te iziskuje dodatnu edukaciju osoblja koja izvodi spojeve, kao i onih koji ih ispituju. Kako se ovdje radi o čeličnim proizvodima, spojevi kod takvih konstrukcija najčešće se izvode varenjem i/ili vijčano pa je stoga vrlo 
važno spojeve izvesti na pravilan način kako bi se dobio proizvod željene kvalitete.

Svi procesi i postupci koji se odvijaju unutar tvornice su jednako važni kako bi se postigao konačni cilj, a to je kvalitetan čelični element sukladno normi HRN EN 1090 za buduću izgradnju građevina. Cilj ovog rada je ukazati na važnost provođenja tvorničke kontrole kvalitete, čime se bitno smanjuje mogućnost pogrešaka, kako tijekom proizvodnje čeličnih elemenata, tako i u slučaju otkazivanja konstrukcije tijekom njenog korištenja. U okvirima ovog rada na primjeru izgrađene spregnute čelične konstrukcije fasade hale prikazan je postupak provođenja tvorničke kontrole kvalitete u skladu sa normom HRN EN 1090.

\section{Tvornička kontrola proizvodnje}

\subsection{Općenito}

Tvornička kontrola proizvodnje (eng. Factory Production Control, FPC) predstavlja niz radnji, odnosno procesa kojima se poboljšava kvaliteta proizvedenog proizvoda te u konačnici ima cilj zadovoljiti očekivanja kupca [1]. Ona znači dokumentiranje i provođenje stalne unutrašnje kontrole proizvodnje u proizvodnom pogonu, a sve u skladu s odgovarajućim usklađenim tehničkim specifikacijama te u skladu s normama.

Pritom tvorničku kontrolu proizvodnje provodi sam proizvođač na način da sve dijelove, zahtjeve i odredbe koje je prihvatio treba dokumentirati na sustavan način u obliku pisanih zapisa i postupaka [2].

\subsection{Sustav tvorničke kontrole proizvodnje}

Sustav tvorničke kontrole kvalitete proizvodnje čeličnih konstrukcija podrazumijeva [2]: kontrolu materijala, kontrolu izrade u radionici, kontrolu pri montaži te kontrolu nanesene antikorozivne zaštite. Sve navedene kontrole, uz kontinuiranu kontrolu radnog procesa samog radnika, obavlja osposobljeni i ovlašteni inženjer kontrole kvalitete. Na taj se način dodatno doprinosi kvaliteti čelične konstrukcije, kao i održavanju razine kvalitete samog procesa tvorničke proizvodnje. Kroz primjer na već izgrađenoj čeličnoj hali prikazat će se upravo procesi kontrole sukladne grupi normi HRN EN 1090 koje su se provodile sa svim svojim obilježjima. Navedenom grupom normi je određena potrebna dokumentacija proizvođača čelične konstrukcije u koju spada dokumentacija o kvaliteti, plan kvalitete, sigurnost na radu te dokumentacija o izvođenju čelične konstrukcije odnosno njenoj proizvodnji.

Postupak tvorničke proizvodnje čelične konstrukcije može se promatrati kao dinamički sustav [7] kojeg, osim ulaza i izlaza u sustav, karakterizira i međusobno djelovanje okoline i sustava [8]. Nakon definirane klase izvođenja i kontrole kvalitete uvjetovane zahtjevima iz norme i projektne dokumentacije, 
postupak proizvodnje čelične konstrukcije vidljiv je iz dijagrama tijeka procesa proizvodnje (Slika 1).

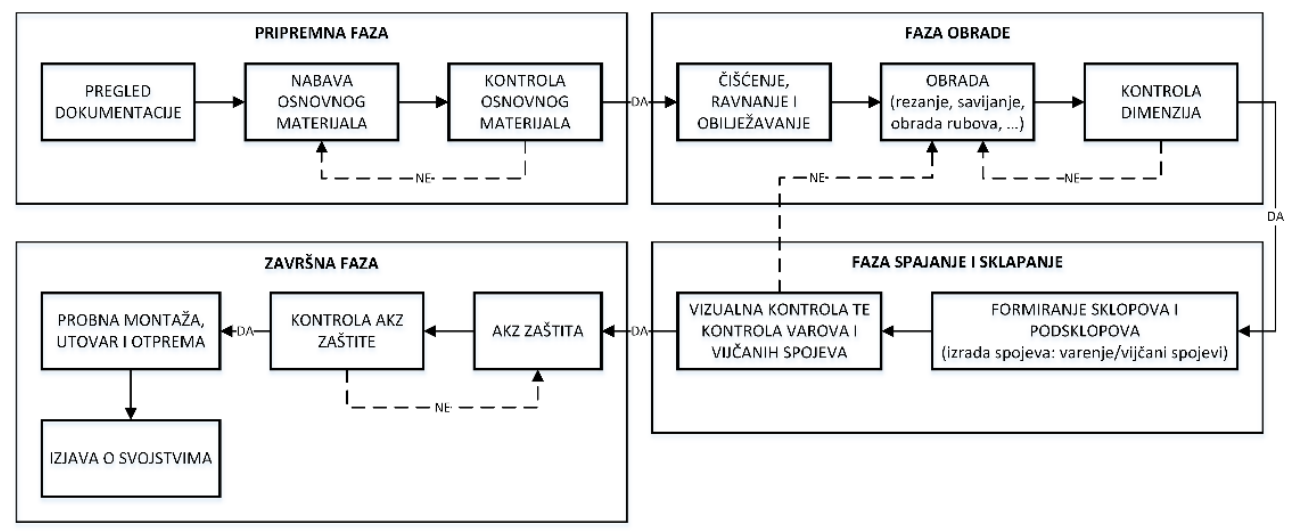

Slika 1. Dijagram tijeka procesa proizvodnje čelične konstrukcije

Proces proizvodnje čelične konstrukcije može se podijeliti u četiri faze kao što je prikazano na Slici 1: pripremna faza, faza obrade, faza spajanje i sklapanje te završna faza. Završna aktivnost svake faze jest kontrola rada izvedenog $\mathrm{u}$ dotičnoj fazi. Ukoliko se kontrolna aktivnost zadovolji, proces proizvodnje kreće naprijed (u novu fazu). U protivnom, čelična konstrukcija se vraća na doradu unutar iste faze, odnosno prethodne faze, sukladno potrebi. Ključna faza u pripremi proizvodnje je pregled i kontrola radioničke dokumentacije. Po pregledu dokumentacije slijedi nabava osnovnog materijala te njegova kontrola. U ovom se koraku prvenstveno radi o internoj kontroli, pri čemu se kontrolira osnovna sirovina. Ustanovi li se da je došlo do pogreške u nabavi ili isporuci materijala, moraju se poduzeti mjere za uklanjanje greške, što rezultira ponavljanjem postupka nabave osnovnog materijala.

Prva faza same proizvodnje nosi naziv „Faza obrade“, pri čemu se osnovni materijal čisti, ravna i obilježava, a potom obrađuje (reže, savija, i dr.) sukladno radioničkim nacrtima. Po završetku obrade slijedi kontrola dimenzija te se u slučaju pogrešaka pristupa ponovnoj obradi ako je moguća. U slučaju kada nije moguće ispraviti pogrešku, takav proizvod se smatra „škartom“ te se skladišti i obilježava na propisano mjesto s naznakom „škart“. Po završetku pregleda dimenzija izrezanih, savijenih te obrađenih čeličnih elemenata, počinje se sa fazom spajanje i sklapanje, što podrazumijeva formiranje sklopova ili podsklopova u cjeline s izvođenjem spojeva varenjem i/ili vijčano.

Tijekom cijele proizvodnje, a naročito tijekom faze obrade te faze spajanje i sklapanje, kontinuirano se provodi vizualna kontrola od strane samog proizvođača, dok se na kraju svih izvedenih spojeva izvodi kontrola varova (ako se radi o spojevima izvedenim varenjem), odnosno kontrola vijčanih spojeva (ako su spojevi izvedeni pomoću vijaka). Navedenu kontrolu varova i vijčanih spojeva provodi ovlašteni inženjer kontrole kvalitete, tzv. IWE inženjer. Kako su pogreške 
u svakom trenutku moguće, u ovom dijelu proizvodnje u slučaju pogreške potrebno je proizvod obraditi na način da se izvede obrada vara ili ponoviti proces obrade u vidu rezanja novog čeličnog elementa. Kao i u ostalim slučajevima kada to nije moguće, proizvod se smatra „škartom“ te se ponavlja proizvodnja od procesa obrade. U slučaju kada svi formirani sklopovi i podsklopovi prođu vizualnu kontrolu, kontrolu varova te kontrolu vijčanih spojeva, pristupa se završnoj fazi procesa proizvodnje čelične konstrukcije koji započinje zaštitom od korozije nanošenjem boja i premaza, odnosno vrućim cinčanjem (tzv. AKZ zaštita). Potom slijedi kontrola antikorozivne zaštite (AKZ) koju također provodi ovlašteni inženjer kontrole kvalitete. U slučaju kada neki čelični sklop ili njegov dio ne zadovolji ovu kontrolu, sami postupak AKZ zaštite se ponavlja. Kao zadnja radna operacija u procesu proizvodnje izvodi se probna montaža na prostoru tvornice te se proizvod potom utovaruje i otprema na gradilište. Završna faza ovog procesa proizvodnje čelične konstrukcije završava izdavanjem izjave o svojstvima za tvornički proizveden čelični proizvod.

Proizvođač mora uspostaviti, dokumentirati i održati sustav tvorničke kontrole proizvodnje na način da pritom osigura da proizvod koji je stavljen na tržište udovoljava svim deklariranim svojstvima. Pritom je u interesu proizvođača svoj tehnološki proces proizvodnje provoditi u skladu kako je to propisano normama čime dodatno doprinosi kvaliteti svog tehnološkog procesa, kvaliteti proizvedene čelične konstrukcije kao i mogućnosti davanja sigurnosti u svoj proizvod čime preuzima odgovornost za sukladnost tog proizvoda putem izjave o svojstvima.

Stoga je poželjno da sustav tvorničke kontrole proizvodnje sadržava pisane postupke, održava redovne preglede i ispitivanja sastavnih proizvoda, procesa proizvodnje i proizvedenih dijelova te ima opisane mjere i procedure. Navedenim se osigurava da osoblje koje je uključeno u proizvodne aktivnosti, a koje utječu na sukladnost sastavnih dijelova čelične konstrukcije, ima jasan i ujednačen slijed faza unutar tehnološkog procesa proizvodnje. Na taj se način ostvaruje konzistentnost u kvaliteti tvorničkog rada, što se odražava na kvaliteti krajnjeg proizvoda, dok, istovremeno, sustav tvorničke kontrole pruža naručitelju sigurnost da će u konačnici dobiti proizvod tražene/ugovorene kvalitete.

Upravo se pravilnim i stručnim provođenjem tvorničke kontrole kvalitete postiže kontinuirana unutarnja kontrola proizvodnje koja rezultira kvalitetnim proizvodom sa svom potrebnom dokumentacijom o svojstvima proizvoda. Osnovna prednost postojanja tvorničke kontrole kvalitete sukladno normama bitno smanjuje mogućnost pogrešaka zahvaljujući kontrolnim radnim operacijama u ključnim fazama proizvodnje koje se u konačnici odražavaju i na troškove tehnološkog procesa proizvodnje. 


\subsection{Pregled zahtjeva za čelične konstrukcije}

Grupa normi HRN EN 1090 [3-5] se odnosi na sastavne dijelove ili komponente koje se trajno instaliraju i/ili ugrađuju u građevinske objekte i čija svojstva imaju utjecaj na bitna obilježja i značajke objekata. Pritom se utvrđuju zahtjevi za ocjenu sukladnosti izvedenih karakteristika za konstrukcijski čelik i aluminijske elemente, kao i za višekomponentne sustave koji se stavljaju na tržište kao konstrukcijski proizvodi.

2.3.1. HRN EN 1090-1:2009 Izvedba čeličnih i aluminijskih konstrukcija - 1. dio: Zahtjevi za ocjenjivanje sukladnosti konstrukcijskih komponenata

Norma HRN EN 1090-1 [3] daje zahtjeve za ocjenjivanje sukladnosti konstrukcijskih komponenti. Specifikacija zahtjeva za ocjenjivanje sukladnosti obuhvaća karakteristike proizvodnje te konstrukcijske proračunske karakteristike. Osnovni zahtjevi za ocjenjivanje sukladnosti čeličnih konstrukcijskih komponenata su [3]: sastavni dijelovi, tolerancije na dimenzije i oblik, zavarljivost, lomna žilavost, otpornost na umaranje, otpornost na požar, reakcija na požar, opasni sastojci, otpornost na udar te trajnost.

2.3.2. HRN EN 1090-2:2008 Izvedba čeličnih i aluminijskih konstrukcija - 2. dio: Tehnički zahtjevi za čelične konstrukcije

Kroz normu HRN EN 1090-2 [4] određeno je koje su specifikacije i dokumentacija potrebna prilikom tvorničke izrade čeličnih konstrukcijskih komponenata tj. čeličnih konstrukcija. Pritom, normom su definirane četiri klase izvođenja (EXC) koje su povezane s proizvodnjom (PC) i uporabnim razredom (SC) te klasom posljedica (CC), kao što je prikazano u Tablici 1.

Tablica 1. Matrica za pridruživanje klase izvođenja, ovisno o uporabnim $i$ proizvodnim razredima [6]

\begin{tabular}{|c|l|c|c|c|c|c|c|}
\hline \multicolumn{2}{|c|}{ KLASE POSLJEDICA } & \multicolumn{2}{c|}{ CC1 } & \multicolumn{2}{c|}{ CC2 } & \multicolumn{2}{c|}{ CC3 } \\
\hline UPORABNE KATEGORIJE & SC1 & SC2 & SC1 & SC2 & SC1 & SC2 \\
\hline $\begin{array}{c}\text { PROIZVODNE } \\
\text { KATEGORIJE }\end{array}$ & PC1 & EXC1 & EXC2 & EXC2 & EXC3 & EXC3 ${ }^{1}$ & EXC4 1 \\
\cline { 2 - 8 } & PC2 & EXC2 & EXC2 & EXC2 & EXC3 & EXC31 & EXC41 \\
\hline
\end{tabular}

${ }^{1}$ Može se primijeniti i EXC3 za specijalne konstrukcije ili konstrukcije s ekstremnim posljedicama pri otkazivanju u skladu s nacionalnim preporukama.

Postupak odabira odgovarajuće kategorije izvođenja može se promatrati kroz tri koraka [6]:

1. korak: odabir klase posljedice

2. korak: odabir uporabne i proizvodne kategorije

3. korak: odabir klase izvođenja 
Tablica 2. Klase posljedica u slučaju otkazivanja nosivosti [6]

\begin{tabular}{|c|c|c|}
\hline $\begin{array}{c}\text { KLASE } \\
\text { POSLJEDICA }\end{array}$ & OPIS & $\begin{array}{c}\text { PRIMJERI } \\
\text { GRAĐEVINA }\end{array}$ \\
\hline $\mathbf{C C 3}$ & $\begin{array}{c}\text { VISOKA } \\
\text { Vrlo velike posljedice zbog gubitka života, } \\
\text { ekonomskih i socijalnih posljedica, kao i } \\
\text { posljedica s obzirom na okoliš }\end{array}$ & $\begin{array}{c}\text { Tribine, koncertne } \\
\text { dvorane itd. }\end{array}$ \\
\hline CC2 & $\begin{array}{c}\text { SREDNJE } \\
\text { Znatne posljedice zbog gubitka života, } \\
\text { ekonomskih i socijalnih posljedica, kao i } \\
\text { posljedica s obzirom na okoliš }\end{array}$ & $\begin{array}{c}\text { Stambene i poslovne } \\
\text { zgrade }\end{array}$ \\
\hline NC1 & $\begin{array}{c}\text { NISKA } \\
\text { M̌ivota, ekonomskih i socijalnih posljedica, kao } \\
\text { i posljedica s obzirom na okoliš }\end{array}$ & $\begin{array}{c}\text { Poljoprivredne } \\
\text { građevine gdje se } \\
\text { skladišnta, zadržavaju, } \\
\text { sl. }\end{array}$ \\
\hline
\end{tabular}

Pritom su klase izvođenja definirane [6] za skladišta i zgrade za poljoprivrednu namjenu (EXC1), zgrade za stanovanje i uredske prostore (EXC2), stadione i dvorane (EXC3) te posebne konstrukcije - mostove velikih raspona (EXC4). U pogledu uporabnih kategorija razlikuju se [6]:

SC1 - konstrukcije koje su izložene nazovistatičkim djelovanjima, seizmičkim opterećenjima i opterećenja zamora,

SC2 - konstrukcije izložene velikim opterećenjima zamora, umjerenim seizmičkim djelovanjima i konstrukcije osjetljive na utjecaje vjetra,

dok su dvije proizvodne kategorije [6]:

PC1 - konstrukcije s komponentima koje nisu zavarivane ili zavarene komponente izrađene od čelika klase ispod S355,

PC2 - konstrukcije sa zavarenim komponentama izrađenim od čelika kase S355 i višim, komponente koje su termički tretirane ili toplo oblikovane te komponente od kružnih šupljih presjeka rešetkastih nosača.

\subsection{Sustav ocjenjivanja i provjera stalnosti svojstva i CE oznaka}

Oznaka CE (franc. Conformite Europeenne) obvezna je na svim proizvodima koji zahtijevaju takvo označavanje prije stavljanja na tržište ili prije uporabe [2]. CE oznaka se stavlja na sve proizvode za koju je proizvođač izradio izjavu o svojstvima te predstavlja sigurnost za koju proizvođač preuzima odgovornost za sukladnost tog proizvoda. 
Navedeno podrazumijeva da je za svaki proizvod označen CE oznakom proizvođač izdao izjavu o svojstvima. U tehničkom smislu, na temelju izjave o svojstvima izrađuje se tehnička dokumentacija koja je sastavni dio isporuke na gradilište.

\section{Primjena norme HRN EN 1090 na primjeru izrade spregnute čelične konstrukcije fasade hale}

U radu je prikazana primjena norme HRN EN 1090-2 na dijelu spregnute čelične konstrukcije fasade hale. Prema Europskoj Direktivi 89/106/EEC, odnosno Pravilniku o ocjenjivanju sukladnosti, ispravama o sukladnosti i označivanju građevnih proizvoda (NN103/08) svi proizvodi od čelika pripadaju u sustav dokazivanja suglasnosti 2+. Projektom je definiran zahtjev za klasom izvođenja EXC2. Konstrukcija fasade izvedena je od stupova i greda kvadratnog profila 200x100x6 (Slika 2) dok su spregovi izrađeni od cjevastih okruglih profila RO 193,7x6,3 (Slika 3) sa uškama sa svake strane, a sve u kvaliteti S355J2. Pozicije sklopova fasade označeni su redom oznakama SF1SF15, a spregovi konstrukcije označeni su oznakama D13-D17. Svi spojevi na sklopovima izvedeni su kutnim zavarom, dok se spajanje sklopova u konstrukciju izvelo pomoću vijaka. Antikorozivna zaštita izvela se bojanjem u dva sloja.

Pregledom tehničke dokumentacije pristupilo se nabavi repro materijala te njegov pregled i pregled atestne dokumentacije. Za sam ulazni osnovni i potrošni materijal utvrđeno je da svi dokumenti o ispitivanju materijala moraju biti „tip 3.1.“ koji izdaje i ovjerava odjel neovisan od proizvodnje koji jamči da se procesi ispitivanja izvode ispravno i nosi oznaku CE.

U pripremnoj fazi izrade čeličnih komponenti izvršeno je čišćenje i obilježavanje čeličnih profila. Sva obilježavanja prethodno su provjerena od strane voditelja proizvodnje kako bi se smanjila mogućnost pogreške te se pristupilo rezanju i izradi rupa.

Po završetku rezanja započinje se sa izradom sklopova. S obzirom da se varenjem izvodi spajanje uški na spregovima te ploče sa rupama na stupovima i gredama, vođen je dnevnik zavarivanja ovjeren i pregledan od strane IWE inženjera, a sve prema radnoj uputi za zavarivanje tj. WPS listi (eng. Welding Procedure Specification). Izvršena je kontrola zavarivanja nerazornom metodom (NDT) - radiografska kontrola za varove na elementima i izdano izvješće (nalaz) o provedenoj kontroli zavara. Svaki element koji je zavaren obilježen je jedinstvenom oznakom koja je dodijeljena svakom zavarivaču. To je način na koji se provodi kontrola te se u svakom trenutku može znati tko je izvodio zavarivačke radove na pojedinom elementu. Pored tih oznaka postavljene su oznake po pozicijama radi montaže kako ne bi došlo do pogreške u montiranju sklopova. 
Tijekom cijele proizvodnje, od rezanja do sklapanja elemenata u sklopove, provodi se dimenzionalna kontrola zavarenih elemenata te vertikalnosti i kutnog razmaka. Tijekom cijele proizvodnje nije došlo do većih odstupanja u dimenzijama i izvođenju zavara te nije bilo potrebe za postupkom za nesukladne proizvode.

Pregledom i kontrolom zavarenih sklopova izvedena je vizualna kontrola utovara te su sklopovi otpremljeni na gradilište gdje se izvela montaža sklopova u konstrukciju. Završni dokument koji je izdan za izvedbu čelične konstrukcije fasade hale je Izjava o svojstvima koja kupcu daje sigurnost i jamči da je čelična konstrukcija izrađena prema svim pravilima norme EN 1090-2.

Izjava o svojstvima je dokument koji sadrži potrebne podatke o proizvođaču, vrsti i namjeni proizvoda te svojstvima proizvoda (dimenzije, tolerancije dimenzija i oblika, zavarljivost, udarna žilavost, reakcija na vatru, trajnost, opterećenja i dr.). Na izjavi o svojstvima potrebno je naznačiti identifikacijski broj tijela za ocjenu sukladnosti te mora biti potpisana od strane voditelja tvorničke kontrole proizvodnje.

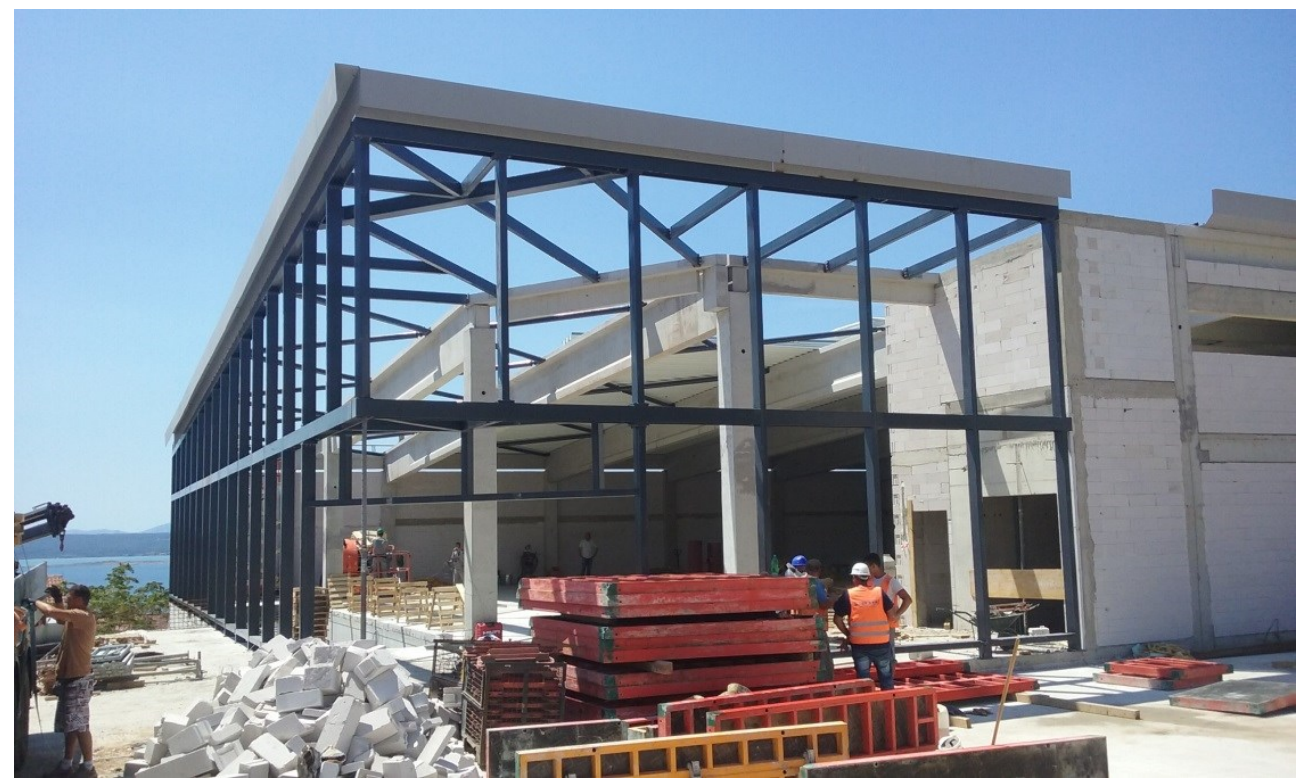

Slika 2. Pogled na konstrukciju fasade kvadratnog profila 


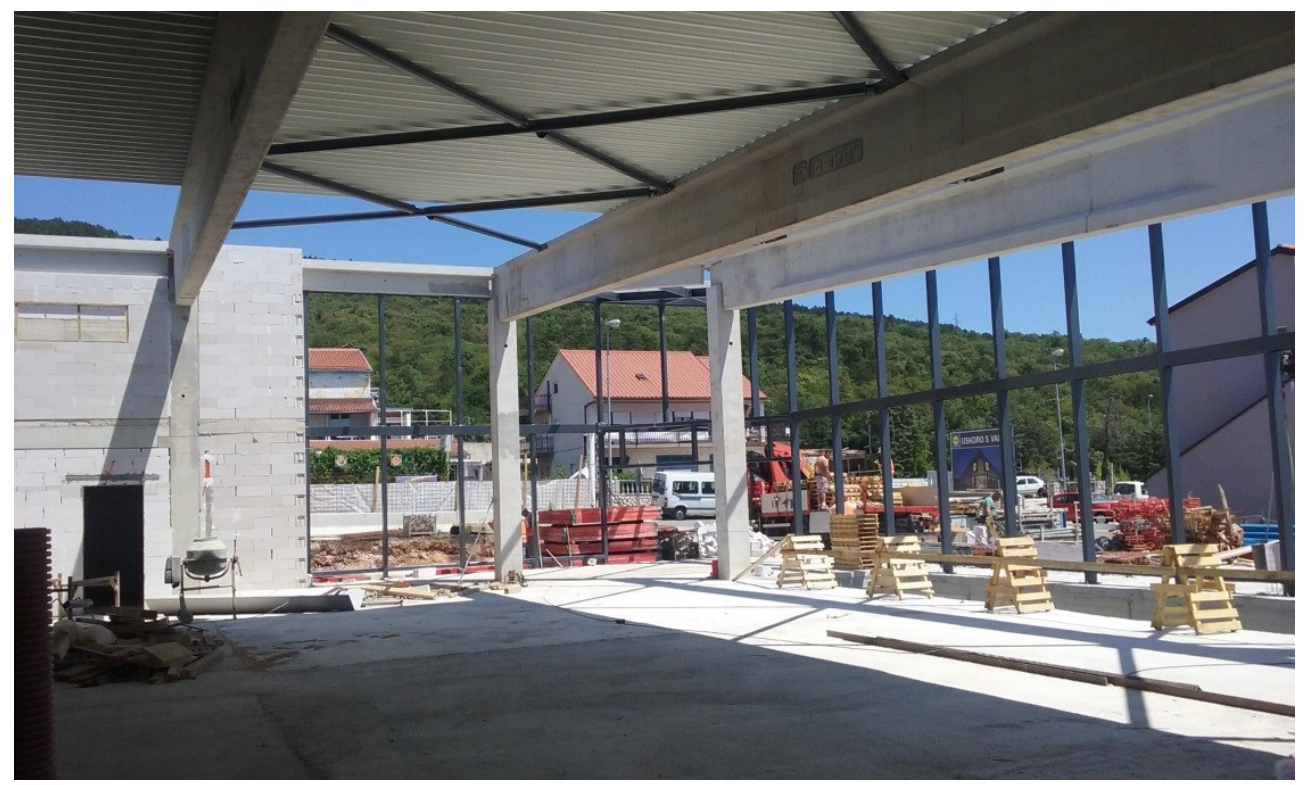

Slika 3. Pogled na spregove cjevastog profila

\section{Rezultati ispitivanja i provedene kontrole}

Ispitivanja i kontrole koje su provedene na projektu provode se od strane vanjskog tijela neovisnog od proizvodnje. Sve izvještaje i dokaze o ispravnosti ovjerava ovlašteni predstavnik tijela nezavisnog od proizvodnje, koji ujedno i jamči da su se sva ispitivanja provela ispravno te u skladu sa svim propisima. Kontrole koje se pritom provode mogu se grupirati i promatrati u obliku kontrole izvedene konstrukcije, kontrole ugrađenog materijala, kontrole postupaka i osoblja te završnog izvještaja o radiografskoj kontroli zavarenih spojeva.

Navedene kontrole su opisane na prethodnom primjeru spregnute čelične konstrukcije fasade hale.

\subsection{Kontrola ugrađenog materijala}

Za sve materijale koji su ugrađeni i korišteni tijekom procesa proizvodnje izdani su tvornički atesti kao dokaz kvalitete. Sav ulazni osnovni i potrošni materijali sukladni su zahtjevima iz projekta te su izdani atesti „tip 3.1“. Pritom, svi dokazi o kvaliteti moraju biti izdani od strane ovlaštenih tvrtki ili ustanova.

\subsection{Kontrola postupaka i osoblja}

Kako bi se osigurala potrebna kvaliteta, tijekom izvođenja radova $u$ proizvodnji provedena je kontrola sposobnosti osoblja (uvjerenja o ispitivanju 
zavarivača), kontrola odgovornih osoba (potvrde o sposobnosti IWE inženjera, kvalifikacije postupaka zavarivanja (WPS liste) te potvrde o izvršenoj validaciji opreme za zavarivanje i kalibriranju kontrolne opreme.

\subsection{Završni izvještaj o radiografskoj kontroli zavarenih spojeva}

Kontrola zavarenih spojeva (kutni spojevi) izvršeni su nerazornom metodom (NDT) - radiografskom kontrolom. Opseg ispitivanja, tehnika snimanja te kriterij prihvatljivosti provedeni su prema zahtjevima iz projekta. Prozračivanje je izvršeno ionizirajućim izvorom Ir 192 aktivnosti 0,98 TBq. Za radiograme je korišten industrijski film AGFA STRUCTURIX D5 10 x 48/ cms Pb folijom.

Za spregnutu čeličnu konstrukciju fasade hale D10 - D17 snimljeno je ukupno 48 radiograma, odnosno za svaki spreg po 6 radiograma, što predstavlja opseg ispitivanja u iznosu od $100 \%$. Radiografskom snimkom utvrđeno je da nije bilo negativnih ocjenjenih radiograma, što u konačnici iznosi $0 \%$ od prihvaćenih.

Za čelični sklop fasade hale SF1 -SF15 snimljeno je ukupno 52 radiograma, što predstavlja opseg ispitivanja u iznosu od $90 \%$. Radiografskom snimkom utvrđeno je da nije bilo negativnih ocjenjenih radiograma što u konačnici iznosi $0 \%$ od prihvaćenih.

\subsection{Kontrola izvedene konstrukcije}

Kontrola izvedene konstrukcije provedena je mjerenjem oblika i dimenzija svih elemenata i sklopova čelične konstrukcije te uspoređena s radioničkim nacrtima. Rezultatima mjerenja utvrđeno je da su svi sklopovi tehnički prihvatljivi te ne zahtijevaju naknadne prerade.

\section{Zaključak}

Radom je opisan postupak provedbe unutarnje tvorničke kontrole proizvodnje kvalitete čeličnih proizvoda u skladu sa normom HRN EN 1090. Na primjeru izgrađene spregnute čelične konstrukcije fasade hale ukazano je na važnost provođenja tvorničke kontrole kvalitete, čime se bitno smanjuje mogućnost pogrešaka, kako tijekom proizvodnje čeličnih elemenata, tako i u slučaju otkazivanja konstrukcije tijekom njenog korištenja. Radom je prikazan i opisan dijagram tijeka procesa proizvodnje čelične konstrukcije sukladno normi te analiziran tijek unutarnjih kontrola tijekom tvorničke proizvodnje. Za ostvarenje ciljeva (smanjenje mogućnosti pogrešaka te otkazivanje konstrukcije tijekom njenog korištenja) potrebno je uspostaviti kvalitetnu proceduru provođenja kontrole kvalitete jasnim procesima i uz adekvatno kvalificirano osoblje. Navedeno omogućava postizanje visoke razine sigurnosti tijekom tvorničke kontrole kvalitete čeličnih proizvoda. 


\section{Literatura}

[1] Juran, J.M.; De Feo, J. (2010) Juran's Quality Handbook: The Complete Guide to Performance Excellence, McGraw Hill.

[2] Ivetić, R. (2013) Tvornička kontrola kvalitete čeličnih proizvoda. Diplomski rad. Osijek. Sveučilište Josipa Jurja Strossmayera u Osijeku, Građevinski fakultet.

[3] EN 1090-1:2009 Execution of Steel Structures and Aluminium Structural - Part 1: Requirements for Conformity Assessment of Structural Components.

[4] EN 1090-2:2008 Execution of Steel Structures and Aluminium Structural - Part 2: Technical Requirements for Steel Structures.

[5] EN 1090-3:2008 Execution of Steel Structures and Aluminium Structural - Part 3: Technical Requirements for Aluminium Structures.

[6] Markulak, D., Bajkovec, I. (2011) Izvedba čeličnih konstrukcija prema europskim normama. Osijek. Sveučilište Josipa Jurja Strossmayera u Osijeku, Građevinski fakultet.

[7] Žaja, M. (1993) Poslovni sustav, Zagreb: Školska knjiga.

[8] Car-Pušić, D., Marović, I., Gudac, I. (2010) Važnost projekta organizacije građenja u pripremi izvođenja građevinskih radova. Zbornik Građevinskog fakulteta Sveučilišta u Rijeci, Vol. 13, str. 225-243. 